\title{
A Recognitional Planning Model ${ }^{1}$
}

\author{
John Schmitt \\ 2801 Valley Brook Drive \\ Champaign, IL 61821 \\ $\mathrm{Ph}: 217-356-8806$ \\ E-mail: schmittzu@aol.com \\ Gary Klein \\ Klein Associates Inc. \\ 1750 Commerce Center Blvd. North \\ Fairborn, OH 45324 \\ Ph: 937-873-8166 \\ E-mail: gary@klein-inc.com
}

\begin{abstract}
Planning under conditions of uncertainty, time pressure, and other stressors is a complex cognitive activity for military command post staff members. The Army and the Marine Corps have developed formal planning models intended as step-by-step guides. However, these models are inconsistent with the actual strategies of skilled planners, and they slow down the decision cycle. As a result, the formal models are usually ignored in practice, in order to generate faster tempo. Yet some procedure is needed, to direct inexperienced staff and to coordinate the actions of a planning team. We present a Recognitional Planning Model (RPM) based on a series of observations of Army, Marine, and Naval command post exercises. The RPM applies the concept of recognitional decision making. The RPM is intended as a prescriptive model to increase the speed of planning, but it is also a descriptive model capturing the strategies of experienced planning teams.
\end{abstract}

\section{Introduction}

Planning under conditions of uncertainty, time pressure, and other stress is a complex cognitive activity. It is also one of the primary functions performed by a military headquarters. Although existing planning models can tend to be very elaborate, they view planning as an orderly, sequential process. They are based on conventional models of human decision making that view decision making as a rational process of multi-attribute utility analysis. The Military Decision-Making Process (MDMP), the U.S. Army's doctrinal planning model, shown in Table 1, is a typical example. It is highly proceduralized, with each of the 7 steps involving numerous prescribed procedures - mission analysis, for example, involves 17 different steps. The Marine Corps Planning Process has 6 steps, and here mission analysis has 13 steps and 9 required outputs.

1 Support for the preparation of this paper was provided by a DARPA/ISO research contract for (DAAH01-99-C-R060). 
Table 1.

The Military Decision-Making Process (U.S. Army)

Step 1. Receipt of Mission

Step 2. Mission Analysis

Step 3. Course of Action Development

Step 4. Course of Action Analysis

Step 5. Course of Action Comparison

Step 6. Course of Action Approval

Step 7. Orders Production

Existing planning models do not do justice to the nonlinear complexity of real planning, and in many cases actually inhibit and degrade planning. Fortunately, most command post staff members ignore these models during operational missions - even during training exercises unless the staff is being scrutinized for compliance with doctrine. However, this situation is not satisfactory. Some planning methodology needs to be used, in order to ensure teamwork and to help new staff members have a blueprint for what to expect and how to frame their roles and functions. If the current planning models are inadequate and inaccurate, then the maxim to "train the way you will fight" is being violated.

This paper proposes a new model for military operations planning, called the Recognitional Planning Model (RPM), which we believe is consistent with both actual military planning methods used in the field and recent research about human decision-making processes [Klein, 1998; Schmitt, 1994; Schmitt and Klein, 1996]. We see the RPM as both descriptive and prescriptive. It is descriptive in the sense that, in our observations, this is the process that planners tend to gravitate towards in naturalistic planning settings. It is prescriptive in the sense that we recognize that planners require some sort of routine to follow. The RPM is presented as a candidate "cognitively correct" routine for command and control settings. The intent is to use the RPM to increase the pace of the planning process.

\subsection{Background}

These conclusions are based on observations of command post operations of U.S. Army, Navy, and Marine Corps units ranging from battalion to corps to JFACC (Joint Force Air Component Commander) in studies dating back to 1995 . Table 2 presents the studies that were used to synthesize the RPM. 
Table 2.

The Identification of Decision Requirements in Command Posts

\begin{tabular}{|c|c|c|c|}
\hline Domain & Decision Requirements & Sponsor & Source \\
\hline Nuclear Power Plants & Emergency management & Duke Power & Klinger \& Klein [in press] \\
\hline JFACC & Development of ATOs & ONR & Klein \& Miller [in press] \\
\hline $\begin{array}{l}\text { Commander Joint Task Force } \\
(\mathrm{CJTF})\end{array}$ & Command Support for JOC & Navy-N6 & $\begin{array}{l}\text { Miller, McDermott, Morphew, } \\
\text { \& Klinger [in preparation] }\end{array}$ \\
\hline USMC Regimental COC & $\begin{array}{l}\text { Plan development } \\
\text { Plan revision }\end{array}$ & USMC/ONR & Klein [1996] \\
\hline USMC MEF & $\begin{array}{l}\text { Plan development and } \\
\text { revision }\end{array}$ & USMC & $\begin{array}{l}\text { McCloskey, Klein, \& Schmitt } \\
\text { [in preparation] }\end{array}$ \\
\hline $\begin{array}{l}\text { Operations Other Than War } \\
\text { (OOTW) }\end{array}$ & $\begin{array}{l}\text { Political and logistical } \\
\text { planning }\end{array}$ & $\begin{array}{l}\text { Natl. Defense } \\
\text { Univ. }\end{array}$ & $\begin{array}{l}\text { Miller, Zsambok, \& Klein } \\
\text { [1997] }\end{array}$ \\
\hline $\begin{array}{l}\text { Enhanced COC for MAGTF } \\
\text { (Hunter-Warrior) }\end{array}$ & Rapid reaction to targets & USMC & $\begin{array}{l}\text { McCloskey, Pliske, Klein, } \\
\text { Heaton, \& Knight [1997] }\end{array}$ \\
\hline $\begin{array}{l}\text { ECOC for MAGTF } \\
\text { (Urban Warrior) }\end{array}$ & Shaping urban battlefield & USMC & $\begin{array}{l}\text { Klein, Phillips, Klinger, \& } \\
\text { McCloskey [1998] }\end{array}$ \\
\hline Command Post of the Future & Command functions & DARPA & $\begin{array}{l}\text { Miller, Hutton, Phillips, \& } \\
\text { Chrenka [in preparation] }\end{array}$ \\
\hline
\end{tabular}

Most of these studies were focused on understanding the planning process itself. Some of the studies were directed at examining the teamwork performed by command post staff as they performed various functions, including planning and replanning.

\section{Objectives Behind the Recognitional Planning Model}

The objectives behind developing this model include:

- Streamlining and accelerating planning operations in general. War is a tempo-based phenomenon. Operators consistently report that the time available for planning is invariably a dominant constraint. Most existing planning models are designed for deliberate planning, with the admonition that steps be combined or compressed when time is short. Our goal was to devise a model that was compatible with time-constrained planning situations.

- Getting the commander, the most experienced person in the organization, more involved in all aspects of the planning process_ - but especially in the critical area of conceptual design. We continuously hear from operators that the commander should be "driving" the process, yet existing models actually inhibit this. This results in a system whereby subordinates generate the options, and bring these to the commander so that he can select among them. Klein, Schmitt, McCloskey, Heaton, Klinger, and Wolf [1996] found that the commander could generate higher quality options than his staff, and in a fraction of the time, so the current procedure is both inefficient and ineffective. Our goal was to create a model in which commanders are expected to provide constructive/creative input rather than merely approving/disapproving or choosing from among existing options prepared by others. 
- Maximizing the involvement of the other most qualified and experienced members of the organization.

- Providing a model that describes the way people actually think and decide in naturalistic settings characterized by time constraints, uncertainty, high stress, and unclear, shifting goals.

- Exploiting the natural skills and experience of people rather than handcuffing those people with unnecessary, mechanistic procedures. Our goal is to exploit the experienced-based human talent for intuition by providing a model that is compatible with the way that talent is manifested and by eliminating steps that are incompatible with our observations of naturalistic decision making.

- Recognizing that planning is not a sequential, linear process. Existing planning models prescribe a linear approach. Our observations indicate that planning rarely, if ever, occurs this way. Rather, different planning activities invariably overlap. Actual planning is an iterative process characterized by frequent feedback loops. Our goal is to provide a descriptive model that captures these nonlinearities.

- Minimizing handoffs and transitions to maximize the retention of learning that takes place during the process. Existing practices (at least at division level and higher) involve a planning section developing the plan and turning it over to the operations section for execution. In many cases there are actually two handoffs: a future plans section develops a concept plan, which it turns over to a future operations section; the future operations section in turn develops an operations or fragmentary order and other execution documents, which it turns over to the current operations section for execution. We observed that much of the understanding that was developed during planning is lost in each transition. We also observed that executors often did not use the execution products provided them by the planners because, not having been part of the planning process, they did not understand the logic behind those documents.

- Emphasizing wargaming, both as a way of evaluating the plan and a way of rehearsing the plan for execution. Our observations indicate that simulation, whether mental simulation done informally or formal wargaming of a course of action, is a central part of the planning and decision-making processes, both in deliberate and hasty situations.

- Arriving at a tentative decision early in the process, to generate tempo and so it can be evaluated, improved, rehearsed, and disseminated, but providing mechanisms for revisiting earlier decisions and returning to earlier stages in the process when necessary. Existing models reserve a decision until the end of the process, often leaving little time to work out the execution of the plan. Our observations suggest that planners are better off arriving at a tentative concept sooner and leaving more time to improve it and to work through the implications and requirements of execution.

- Recognizing that good planning can be an extremely valuable learning experience. The stated objective of planning is to generate a product - a plan. But we observe that one of the most important benefits of planning has nothing to do with generating a plan: people plan because planning provides a rigorous, structured way to learn about a problem space and therefore develop judgment. Our goal is to provide mechanisms to capture the learning benefits of planning, both for planners and executors. 


\section{The Basic Recognitional Planning Model (RPM)}

Any planning process begins with the recognition of the need to plan for some future action. This may come in the form of a directive from higher authority, or planners may themselves recognize the need. The RPM assumes existing situational awareness about the domain before planning begins for a particular mission. We consider this situational information as an initial input to the planning process. If there is not sufficient awareness about the domain, then creating this must precede the planning process. This building of general situational awareness may resemble planning activities, but we do not include this within planning per se, which we interpret to occur in relation to a specific mission. The basic RPM is shown in Figure 1.

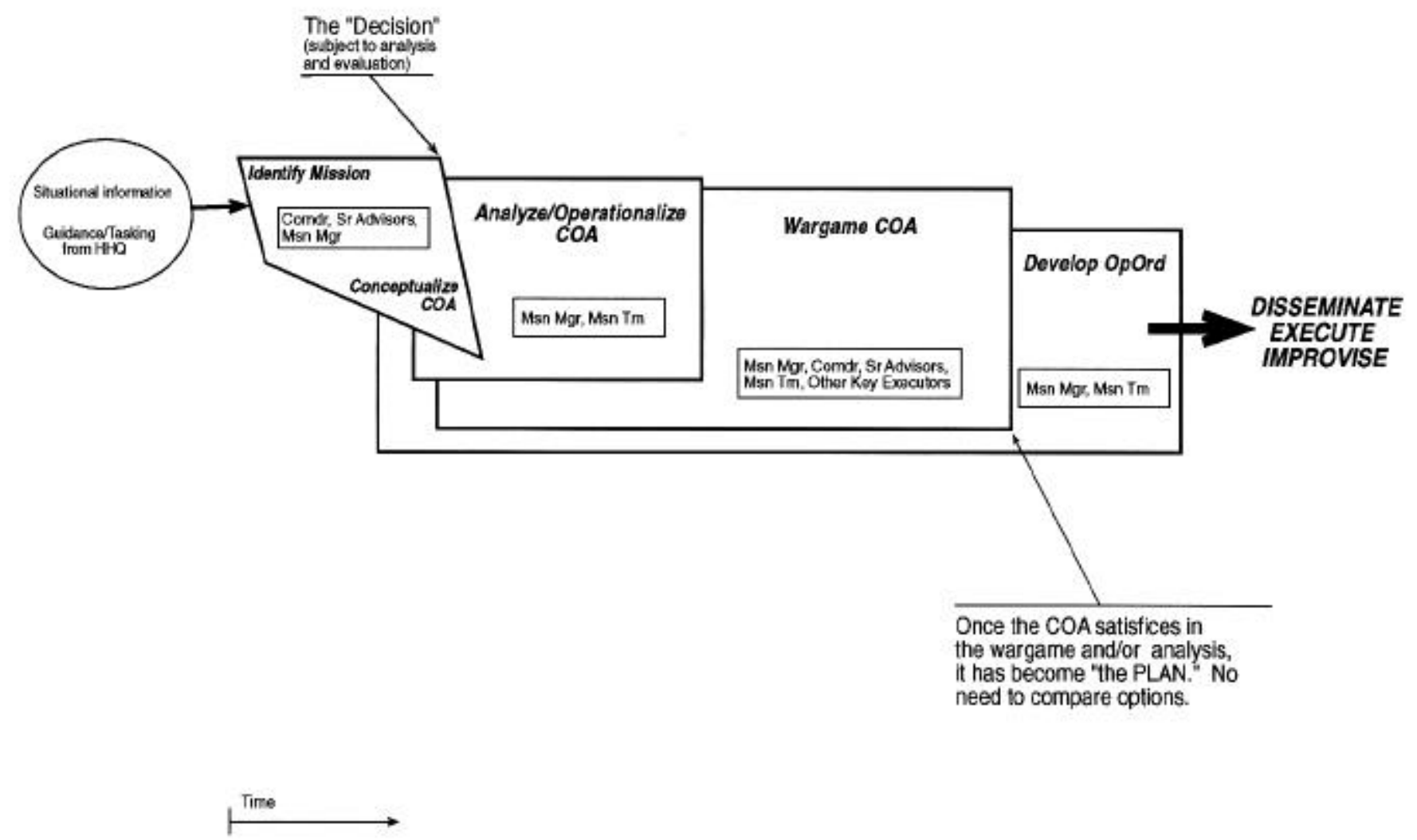

Figure 1. Recognitional Planning Model (Basic) 


\subsection{Identify the Mission/Conceptualize a COA}

Existing models invariably begin with a step typically called "Mission Analysis," which is followed by another typically called "COA Development." The idea is that these activities logically follow in succession. Planners are often warned not to begin developing courses of action (COAs) until they have thoroughly analyzed the mission. We have not observed this distinction to be true. In our observations, planners naturally identify the mission and conceptualize a rough COA simultaneously. In fact, based on our observations, we believe that effective planners conceptualizing a COA helps to clarify the mission: planners gain a better understanding of the problem by posing and then working through potential solutions. As a result, there is a very tight and continuous mutual feedback loop between mission identification and COA creation.

Our choice of terminology, and its difference from existing models, is meaningful. In our observation, identifying the mission is not necessarily an analytical process, as existing models prescribe. The Army's Military Decision-Making Process (MDMP), sees the first phase of planning after mission receipt as a process of thorough analysis involving 17 steps. Some analysis is in fact often required, but we have also observed many planning situations in which planners demonstrated an immediate, intuitive grasp of the mission and did not need to perform any meaningful analysis. Likewise, the MDMP describes the third phase of planning as "COA Development" and has another list of prescribed procedural activities. In our observation, deciding on a COA is not a developmental process, in the sense that development is typically understood to mean a progressive, cumulative building. Rather, deciding on a rough course of action is an inventive activity in which decision makers often describe the concept as springing to mind fully formed in its essence.

Existing models involve the creation of multiple candidate COAs which will eventually be compared against one another later in the process. Earlier research [described in Klein, 1998] indicates that decision makers in naturalistic settings rarely compare courses of action developed in parallel, but instead consider courses of action in sequence until they find one they think will work-often the first one considered. We have observed the same phenomenon in planning. Planners generally recognize very quickly what is the preferred course of action. As a result, planning procedures that require the creation of multiple COAs are artificial and, in our observation, do not improve the quality of plans. The RPM does not prohibit the consideration of multiple COAs, but it envisions a single COA being considered at any time.

"Identifying the Mission/Conceptualizing a COA" is a part of the planning process requiring the direct participation of the commander. This phase is where the truly fundamental judgments are made, and the commander, the most experienced person in the organization, should be at the heart of this_-and not merely as the approver of somebody else's ideas, but as a creative, directing force. At this stage in the process, we see the commander as the chief planner. In small headquarters organizations (such as at the company level), the commander may perform these functions alone. At all echelons, we often see the commander relying on a small group of his most experienced and trusted advisors for input into this process. Even in organizations with large staffs, this type of activity is best performed in small groups of no more than five to six; it is not an activity suitable for a large planning team. 
The outcome of the "Identify/Conceptualize" phase is a decision-a tentative concept of operations. Moreover, it is one that is arrived at very early in the planning process rather than near the very end of the process as in existing models. This early decision is important for several reasons. First, it generally accelerates the tempo of planning, a consideration that can be of fundamental importance in military operations. Second, it facilitates parallel planning. An early decision, even in rough form, may allow other echelons and organizations to begin their own planning sooner. Third, where in existing models candidate COAs remain static until one is chosen, early selection of a COA in the RPM allows for the continuous improvement of the concept as more is learned about the situation and the execution implications of the concept itself. Fourth, and perhaps most important, an early decision allows more time to work out the practical implications of executing the plan. What matters in the end, of course, is execution. In our observations, a good concept well executed is superior to a superior concept poorly executed.

\subsection{Analyze/Operationalize the COA}

Once a COA has been decided on in concept, it must be analyzed and operationalized. Again, these are activities that are performed simultaneously. Actually, they have already begun to occur in "Identify/Conceptualize," as shown by the overlap in Figure 1. We have concluded that planners cannot conceptualize a reasonable COA without some idea of its feasibility or how it will be executed.

By "analyze" we mean evaluating the COA as to feasibility, identifying requirements and potential problems, and working through the implications of the concept. Typical questions to be answered by analysis include:

- Is the COA logistically supportable?

- What are the lift/surveillance/fire support/etc. requirements, and are sufficient assets available?

- Will the successful execution of the COA meet the requirements of the mission?

- By "operationalize" we mean decomposing the broad concept into executable tasks that can be assigned to subordinates for action, and establishing necessary coordination measures between those separate tasks. Operationalizing includes:

- Devising missions (to include intent) for subordinates.

- Allocating forces and assets to those subordinates.

- Establishing command and support relationships.

- Establishing intermediate objectives and other control measures.

- Working out sequencing and other timing issues.

- Developing supporting functional plans for intelligence collection, logistics, fire support, etc.

This phase of the RPM corresponds to what is commonly called execution planning. Much of this phase is largely mechanical, and we envision that automated planning applications can provide a significant assistance. 
The commander may or may not be directly involved in this phase of planning. Especially in small headquarters, he may perform most of this work himself or may be assisted by a small staff. In large headquarters, the commander may likely step out of the process altogether at this phase, leaving these activities to the planning team.

This phase of planning is itself hierarchical, progressing from relatively coarse-grained to relatively fine-grained decisions. For example, we observed a regimental commander leading the early stages of this part of the planning process personally, making general airlift and fire support allocations with his battalion commanders, before turning over to the staff the process of working out the more detailed issues of allocation.

\subsection{Wargaming}

Klein and Crandall [1995] have shown that the ability to perform mental simulation is essential to recognition-primed decision making. We have observed that the same applies to planning, in which context we have called it wargaming. This wargaming process actually underlies much of the earlier stages of planning, all the way back to "Identify/Conceptualize," as shown in Figure 1. Simulating the unfolding plan, whether mentally or through a more formal gaming process, is the vehicle by which the plan is analyzed and operationalized. In our observation, this simulation function (whatever form it takes) is central to effective planning.

Wargaming may not necessarily be a separate phase distinct from "Analyzing/Operationalizing." This is especially true at lower echelons, where any wargaming is probably done informally. On the other hand, especially at higher echelons in deliberate planning settings, wargaming may no longer simply underlie other phases but may become a distinct and formal phase in its own right.

Obviously, a key function of wargaming is to validate the plan with respect to probable or possible enemy COAs. In theory, any inadequate plan should be invalidated during this phase. In our observation, it is unlikely that a flawed plan will survive to the wargaming phase without having been invalidated by the analysis taking place in earlier phases. We did not observe any examples of a COA being invalidated during wargaming. Instead, we found that the wargaming served a critical function of providing a platform for learning. As a result, if a COA has survived this far, wargaming serves less of a validation function and takes on more of a mission rehearsal function. It is an opportunity to resolve coordination issues and to work out likely contingencies. In other words, wargaming serves the needs not only of planners but also of executors. It serves not only the making of the decision but the execution of the decision. For this reason, if the commander and other key executors have stepped out of the planning process in the previous phase, they should return for wargaming.

Existing planning models typically involve wargaming each friendly COA (usually three) against the most likely enemy COA. Time permitting, the RPM envisions wargaming the single friendly COA against several enemy COAs, increasing the situational understanding that is gained. At the end of this phase, if a COA has satisficed against several enemy COAs, it is by definition satisfactory. It becomes "the plan." There is no reason to compare it against other candidate COAs. 


\subsection{Develop the Operation Order}

Once the COA has satisficed in wargaming and become "the plan," all that remains is to produce the necessary execution documents. Actually, this process does not begin after wargaming, but has been going on since the earliest stages of planning. (See Figure 1.) Many of the planning products required for execution should have been developed in earlier stages. We have observed that some organizations are much better at this than others. If done properly, this phase should not delay execution much. It is our belief that this is another area in which automation may accelerate the planning process—by automatically capturing the plan in proper document form as the cognitive part of planning is performed.

As with earlier phases, the commander (and senior advisors) may or may not be directly involved in this phase. In any event, he approves the final product prior to dissemination.

\section{Other Key Features of the Recognitional Planning Model}

Figure 1 shows the basic RPM, which generally is the prescriptive part of the model. In our observations, actual planning is not nearly this simple or sequential. Figure 2 is a descriptive model of what can happen in a typical planning situation.

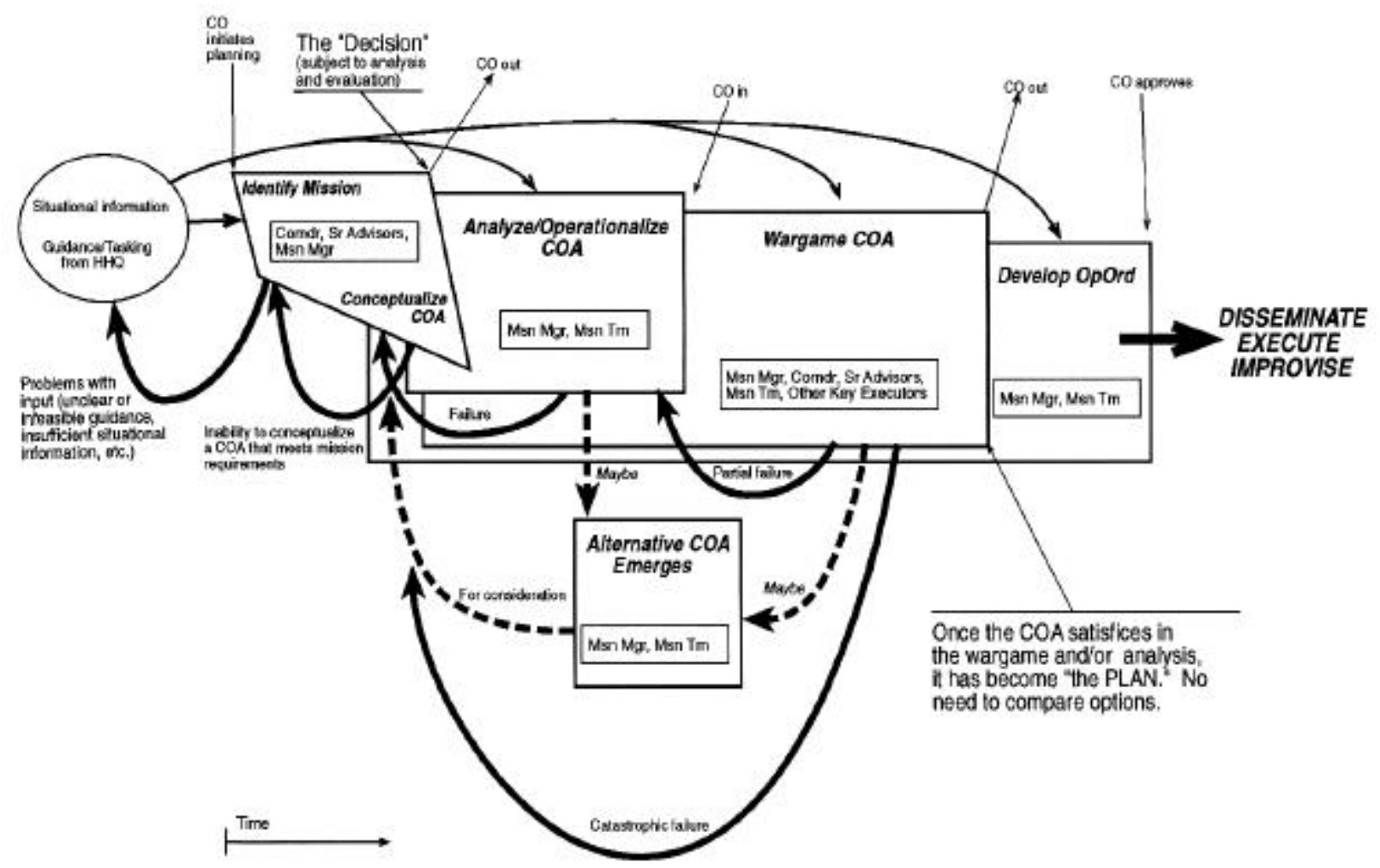

Figure 2. Recognitional Planning Model (Full) 


\subsection{Feedback}

One of the key characteristics of the RPM is the existence of numerous feedback loops. In our observations, planning does not progress sequentially from one phase to the next. Rather, it evolves iteratively through frequent feedbacks. At any point in the process, a COA may fail, requiring feedback to an earlier phase. This failure may be catastrophic, requiring that an entirely new COA be invented, or it may be partial, requiring the adjustment of the existing COA. For example:

- It may be impossible to create a COA that satisfies the stated mission requirements given the available resources. A new mission must be negotiated or decided upon.

- The commander may conceptualize a COA, which is then turned over to the planning team for analysis. The planners discover that the plan is infeasible-it cannot be supported logistically, for example. A new COA must be developed.

- In wargaming, problems arise with the execution of the COA. These do not invalidate the COA in essence, but they require that the $\mathrm{COA}$ be re-operationalized to resolve the execution issues.

- In wargaming, a COA may fail catastrophically, requiring that a new COA be invented. We have never observed this occurrence. We consider it unlikely that a flawed COA will survive this far without being invalidated, but the RPM recognizes the possibility.

\subsection{Emergent COAs}

We have observed that alternative COAs may emerge spontaneously at any time during the planning process, and the RPM captures this. For example, the commander conceptualizes a COA and turns it over to the planning team for analyzing and operationalizing. While the planners perform this analysis (and increase their understanding of the problem space in the process), an alternative COA may occur to them. This alternative COA may be an entirely new concept, or it may be a variation on the existing COA. In either event, the planners may decide this alternative COA warrants consideration and may submit it to the commander, who may accept it, modify and accept it, reject it, or tag it to be developed in parallel with the initial COA.

If a new and different COA emerges during the planning process, there is a chance that a commander will have to make a choice. However, this choice will be between a satisfactory option and one that might be even better. Note how this differs from the current drill in which two inadequate COAs are often generated as fillers to comply with the directive to consider three COAs. Instead of moving through a charade of choice, the RPM is raising the bar to permit a meaningful choice.

\subsection{Single COA Improved Over Time}

There is nothing to prevent a commander from developing multiple COAs in parallel, but the RPM envisions a single COA. In our observation, this COA does not remain static but is modified and improved throughout the process in response to new information or the results of analysis and wargaming. This is accomplished through the major feedbacks between phases and the iterative feedbacks within phases. With existing planning models, multiple COAs considered concurrently 
generally remain static from the time they are created until they are compared. Deciding on a single COA early in the process allows for the continuous improvement of that COA throughout the process. Any alternative COA must now be deemed better than a COA that has been improved continuously rather than a COA that has remained static.

If a COA is invalidated at any phase in the process, a new COA is conceptualized and similarly improved throughout the planning process. The conceptualization of this new COA benefits from the learning that has taken place in the development of the previous COA. With existing planning models, in which multiple candidate COAs are conceptualized in parallel, this advantage does not exist.

A common criticism is that the RPM will sacrifice a lot of potentially critical time if a single COA is invalidated late and planners must return to the beginning of the process. We have two responses. First, it will take less time to conceptualize, develop and invalidate a single COA, and then go back and generate a second than it will to conceptualize, fully develop and then compare several candidate COAs before making a decision. Second, in our observation, it is rare for the initial COA to be invalidated in toto. Most often, the initial COA is workable, with some alterations.

\section{Conclusions}

The RPM is intended to describe a methodology that will enable command post staff to train the way they fight. It is a descriptive model, representing the planning activities observed in a wide variety of exercises. And it is a prescriptive model, presenting a set of activities that can be used to direct the activities of a planning unit.

The RPM is designed to support the planning process, but it is also applicable to the activity of replanning, which is even more time pressured. In one incident, an Army division-level planning cell of four officers was able to generate a fragmentary operation order in 35 minutes, by relying on the scheme showed in Figure 2. They did not bother with multiple COAs. They immediately appreciated how the plan needed to be changed, so they could set to work in building the graphics and text needed to disseminate the FragO. However, during that process, they were finding inconsistencies and alterations, so they were modifying the plan even as they were documenting it.

Another function of the RPM is to identify aspects of the planning process that can be best supported by knowledge-based systems. The analysis and operationalization of the COA is one opportunity, to assist in execution planning. The development of documentation and dissemination materials is another. In contrast, the generation of the COA does not appear to be a suitable candidate for planning support tools. This requires the spark of creativity that generates the essence of a concept of operations. Mintzburg [1994] describes this part of planning as a "black box" activity. Attempts to perform this function by analytical procedure generally result in sterile, unsatisfactory concepts. Our intent in raising this distinction is simply to identify those parts of planning in which there is no procedural substitute for insight and expertise. 


\section{References}

Klein, G. Sources of power: How people make decisions. Cambridge, MA: MIT Press, 1998.

Klein, G. Identification of decision requirements in the U.S. Marine Corps regimental command post. Paper presented at the Proceedings of the Second International Command and Control Research \& Technology Symposium, Warwickshire, England, 1996.

Klein, G., \& Miller, T. E. Distributed planning teams. International Journal of Cognitive Ergonomics, in press.

Klein, G., Phillips, J. K., Klinger, D. W., \& McCloskey, M. J. The Urban Warrior Experiment: Observations and recommendation for ECOC functioning (Contract \#SYN-S01- 8291-54 for Synetics Corporation, King George, VA). Fairborn, OH: Klein Associates Inc., 1998.

Klein, G., Schmitt, J., McCloskey, M., Heaton, J., Klinger, D., \& Wolf, S. A decision-centered study of the regimental command post (Final Contract USC P.O. 681584 for the Naval Command, Control and Ocean Surveillance Center, San Diego, CA). Fairborn, OH: Klein Associates Inc., 1996.

Klein, G. A., \& Crandall, B. W. The role of mental simulation in naturalistic decision making. In P. Hancock, J. Flach, J. Caird, \& K. Vicente (Eds.), Local applications of the ecological approach to human-machine systems (Vol. 2, pp. 324-358). Mahwah, NJ: LEA, 1995.

Klinger, D. W., \& Klein, G. Emergency response organizations: An accident waiting to happen. Ergonomics In Design, in press.

McCloskey, M. J., Klein, G. \& Schmitt, J. Decision making in the Marine Expeditionary Force Combat Operations Center, in preparation.

McCloskey, M. J., Pliske, R. M., Klein, G., Heaton, J. K., \& Knight, B. J. Decision skills training: Preparing Marine squad leaders for Hunter Warrior (Technical report submitted to SYNETICS Corporation for Commandant's Warfighting Laboratory, Special Purpose Marine Air-Ground Task Force under Contract No. N00178-95-D-1008, King George, VA). Fairborn, OH: Klein Associates Inc., 1997.

Miller, T. E., Hutton, R. J. B., Phillips, J., \& Chrenka, J. Command post cognitive demands: Opportunities to support command decision making, in preparation.

Miller, T., McDermott, P., Morphew, M. E., \& Klinger. D. W. Decision-centered design: Cognitive Task Analysis, in preparation.

Miller, T. E., Zsambok, C. E., \& Klein, G. Commander's cognitive demands in OOTW (Final Report for National Defense University, Washington, DC DADW49-98-P-0009). Fairborn, OH: Klein Associates Inc., 1997.

Mintzberg, $\mathrm{H}$. The rise and fall of strategic planning: Reconceiving roles for planning, plans, planners. New York: The Free Press, 1994. 
Schmitt, J. F. Mastering tactics. Quantico, VA: Marine Corps Association, 1994.

Schmitt, J. F., \& Klein, G. Fighting in the fog: Dealing with battlefield uncertainty. Marine Corps Gazette, 80, 62-69, 1996, August. 